\title{
AMARAL, Ronaldo. Santos imaginários, santos re- ais: a literatura hagiográfica como fonte histórica. São Paulo: Intermeios, 2013.
}

\author{
José Walter Cracco Junior ${ }^{1}$
}

O livro Santos imaginários, santos reais. A literatura hagiográfica como fonte histórica que aqui nos propomos a resenhar levanta problemáticas que concernem a relação entre hagiografia como fonte histórica e o Imaginário. $\mathrm{O}$ autor almeja no âmbito das manifestações maravilhosas do imaginário a mesma relevância histórica nas esferas referentes às expressões sociais, econômicas e políticas. À vista disso, Ronaldo Amaral nos propõe reflexões acerca das relações entre a História, a Literatura e o Imaginário, cuidando em seu livro de reafirmar a importância das hagiografias para que possamos vislumbra-las à luz do passado tardo-antigo e medieval, bem como mostrar alguns caminhos para que os historiadores possam recair sobre elas seus olhares e se atentar às riquezas socioculturais que esses escritos compartilham acerca de um imaginário, que bem nos conta o autor, é sempre coletivo.

Portanto, na introdução e no capítulo um intitulado A hagiografia como fonte histórica. O imaginário relegado nos é apresentada, e somos levados a entender, as discussões teóricas no campo da história e do

\footnotetext{
${ }^{1}$ Graduando do curso de História da UFMS-CPTL, bolsista do Programa Institucional de Iniciação à Docência (PIBID).
} 
imaginário onde ele se torna, por excelência, em ferramenta teóricometodológico para análise da História. Os embates que concernem ao uso da literatura, em especifico a literatura sagrada, como fonte histórica foram propiciados pela descoberta de novos métodos e teorias, nesse sentido seria uma heresia não mencionarmos a importância dos bolandistas, que por sua vez, compilavam erudições críticas de textos dedicados a santos, mesmo que naquela instância almejavam dados concretos que afirmassem uma existência real. Amaral também trata neste capítulo a importância de Hippolyte Delehaye ao ampliar os métodos bolandistas em que impunham problemas ao histórico da vida dos santos e buscava fatos verdadeiramente históricos, ou seja, para além do "fictício". Todavia, já teria esse autor chamado a atenção para a hagiografia como fonte histórica, mesmo que seus métodos o levassem para um viés positivista em almejar a verdade objetiva, por consequência, separando o histórico do imaginário, o que Amaral em seu livro não propõe a separação da vida sociomaterial do imaginário. No entanto, é impreterível analisarmos as inovações de Delehaye a sua época, possibilitando assim entender à hagiografia como fonte histórica.

Ainda neste capítulo o autor trata que a partir do imaginário surgem hábitos, costumes e comportamentos capazes de apresentar a razão humana para o homem medieval onde suas bases fundantes estão arraigadas nas sensibilidades, nas estruturas do pensamento simbólico e analógico ao invés de pensamentos idiossincráticos forjados. Nesse sentido, nos é apresentado críticas por parte do autor aos métodos de tratamento dos santos de existência literária como não históricos. No que tange ao 
refutamento dos santos criados pelo imaginário dos hagiográficos o autor rebate isso afirmando que todo santo fictício é um santo por excelência, pois cumpre sua razão a ausência que viria a responder, assim sendo, muitas vezes os santos são personagens ideais no caráter personificado da santidade e que os hagiógrafos não puderam lhe escolher, foram assim, impostos por suas circunstâncias espaço-temporais próprias buscando atender as necessidades materiais e mentais de seu período histórico. Desta forma, fica evidente para o autor que sua historicidade concreta pouco importa, mas sim os atributos supra-humanos do santo.

No capítulo dois A emergência do imaginário nas fontes hagiográficas o autor menciona a hagiografia como texto literário capaz de interessar ao historiador por lhe oferecer uma fonte ordenada, cujo estudo linguístico facilita o trabalho que contempla seu contexto dentro do fenômeno histórico. Amaral, tanto neste capítulo como em outros, irá inaugurar um debate historiográfico onde contrapõe historiadores que afirmam o sincero não ser histórico, mas sim o verdadeiro ser histórico. Nessa acepção o autor levará algumas páginas discutindo o que seria a verdade, sobretudo a verdade histórica, e defende que a "realidade" apresentada pelas hagiografias não devem ser julgadas por métodos, mas sim serem entendidas na categoria do verossímil ao invés do sincero e verdadeiro. Assim sendo, por tratar a hagiografia de uma história sagrada seu teor de verdade também não deve ser buscado nas circunstancias e ideários no lugar daquele que fala, senão no lugar do qual se fala. Como afirmação de seus entendimentos o autor nos diz que as rea- 
lidades fundadas em imagens e situações maravilhosas concebidas pelo imaginário são uma realidade tão verdadeira como a histórica.

Amaral continua por acentuar que à hagiografia interessa ao historiador enquanto o ajude na compreensão da vida social de sua época, embora sempre esteja atrelada a um processo histórico mais amplo, visto que a hagiografia é sempre um "recriar", no entanto, devem ser vistas para além das estruturas econômicas e políticas, ou seja, deve ser concebida pelo imaginário. No discorrer do capítulo encontramos novas críticas, tanto benévolas como nefastas, a renomados historiadores, como Peter Brown e Santiago Castellanos a exemplo, sendo este último mais questionado, pois é partidário que a hagiografia não atende ao caráter de documento histórico, mas, apenas, pode ser tratada como fonte marginal e ser "desmentida" a partir de documentos ditos "oficiais". Para isso, o autor nos ensinou que o que se almeja nas hagiografias é uma realidade menos precisa do que a dos documentos oficiais, visto que é menos carregada de ideologias do que tais documentos. Por meio dessas considerações o autor entende que a hagiografia é uma realidade construída e constitutiva por seus autores, uma vez que o autor é sempre o porta-voz de seu meio, concretizando assim a função do imaginário coletivo e dos ideais da comunidade. Após direcionar seus entendimentos, Amaral defende que o imaginário é um modo de apresentar a História.

No capítulo Hagiografia, biografia e história o autor irá questionar em conjunto com Jacques Le Goff, Loriga, Schwob, Pierre Bourdieu e outros autores a realização das biografias antes da modernidade, pois 
essas não são capazes de apresentar significações históricas gerais no que concerne uma vida individual, nesse viés, o autor nos propõe utilizarmos para investigar o período medieval não a biografia, mas sim intentos biográficos. Assim, no que diz respeito ao "processo biográfico" da vitae dos santos, esse se ocupa mais com as pródigas realizações sagradas do que com o teor laico e a exatidão espaço-temporal, no entanto, Amaral não despreza que as vitae tragam informações de uma existência mais factível dos santos, porém toda informação "factível" nas hagiografias está mergulhada no imaginário, em circunstâncias fundamentadas e objetivadas no fabuloso, milagres, aparições demoníacas, curas e lugares estão ligadas por uma função simbólica que se remete mais a uma realidade transcendente do que factível. É ressaltado por Amaral que a inconsistência histórica acerca do personagem hagiográfico, quando se deseja a biografia, não está na fonte mesma, mas sim na abordagem do historiador, desta forma, a hagiografia trata de homens que deixam de sê-lo ao se tornarem, por sua escrita, santos, ou nas palavras do autor:

"O hagiógrafo cria o santo e para tanto recria sua personalidade histórica, ou seja, aquela, talvez a única, dada a conhecer pela história; assim, haverá na hagiografia sobretudo um santo e, portanto, um homem cuja história ficará, em grande medida, identificada mais com uma existência fabulosa que eminentemente profana" (p.75).

Seguindo esse pensamento, nos é apresentado uma crítica do autor acerca da pretensão da hagiografia como biografia, pois entende que seria algo faltoso, visto que é inviável "resgatar" uma personalidade 
histórica factível e dá-la a conhecer posteriormente, mesmo munido de fontes. É muito latente no livro a questão de quando nos referimos a vida dos santos devemos nos ater mais ao espírito do discurso do que em sua letra, pois é neste que se emerge significados mais precisos da escrita e é ainda mais arraigado quando investigado pela ótica do imaginário.

O autor utiliza esse capítulo terceiro para assentar seu modus cogitare em que à hagiografia é constituída por verdade, sinceridade e realidade, isso porque, suas narrações se assentam em tempos, lugares e acontecimentos que antes de tudo são representações, portanto, as hagiografias são constituídas de lugares e situações ideais apresentadas por signos de transcendência, estruturas simbólicas e espaços do mítico e não por meros dados factíveis e positivos. Outro ponto fulcral tratado neste livro é quando o hagiógrafo é hagiografado, ou seja, quando descreve a si mesmo, para isso o autor traz exemplos de Valério do Bierzo, monge eremita que atribuía a si virtudes das vidas de outros padres do deserto. Para Amaral, esses eremitas mostravam tanta admiração por aqueles santos de sua mesma profissão monástica que imitá-los seria algo grandioso. Há também que se considerar a apropriação literária no âmbito hagiográfico na Idade Média, que seria mais do que uma subtração de textos e palavras das fontes, seria o que o autor chama de "aggiornamento" com adequações do lido e apropriado pelo autor vivido.

Referente ao capítulo quatro A natureza do tempo e do espaço na hagiografia, é explicitado a percepção do tempo e espaço profano/sagrado no imaginário de monges primitivos onde as noções de espa- 
ço geográfico - deserto, árido ou floresta - é mais do que um lugar, é um não lugar, isto é, um lugar que rompe com lugares humanos e seu próprio mundo temporal. Desta forma, os lugares assentados nas hagiografias sempre se remetem a imagens de caráter divino transcendental do que propriamente em espaços geográficos materiais. Portanto, o autor vislumbra que os lugares mais importantes nas hagiografias são os lugares da santidade, os lugares se tornavam santos pela presença do santo propriamente dito que não carregava consigo pecados e por essa sua santidade tornava os lugares sagrados. Nesse intento, somos levados a entender que os lugares apresentados pelas hagiografias são mais do que descrições de lugares concretos passam a ser símbolos que revertem significantes profanos os tornando sagrados com efetiva participação dos santos, como os desertos.

Nos é apresentado ainda neste capítulo o quão os espaços geográficos de desconhecimento dos homens medievais eram concebidos por uma dimensão mítica e fabulosa, com isso, o autor quer ressaltar em sua obra que o espaço era pensado mais em totalidade do que parcialidade. Amaral diz ser "auspicioso" buscar nas hagiografias um estrito espaço geográfico exato, visto que na Antiguidade Cristã os espaços serviam para separar o eremita da sociedade, portanto essa cisão de espaços dentro das hagiografias é interpretada como uma cisão para com a realidade cósmica. Nesse sentido, Amaral defende neste capítulo que os santos conseguem romper com o tempo ordinário ao se transportar miraculosamente no tempo e no espaço presenciando assim lugares distintos e longínquos em tempo curto. Desta forma, cabe ao escritor da vida do 
santo solitário demonstrar o lugar que ele não está, ou seja, extramundano, longe da sociedade e do pecado. O autor encerra este capítulo com a reflexão em que a vida e feitos de santos se desenvolvem em uma temporalidade da santidade, e não obedecem uma dinâmica aberta, portanto, os santos estão acima e além do espaço mundano.

No que concerne ao quinto e último capítulo Hagiografia: a tradição da escrita, a escrita da tradição, o autor nos coloca como latente a perícia que historiador tem para fazer emergir de um texto uma realidade, todavia, isso é possibilitado, e Amaral defende essa possibilidade, por meio de uma interpretação hermenêutica dos textos onde se objetiva atingir e extrair o espírito do texto, ou seja, a "vivência subjetiva do autor" que corresponderia ao seu meio sociocultural e mental. Nesse sentido, entendemos que para compreensão de um texto ou uma fonte deve-se levar em consideração todas as suas possibilidades de interpretação, ou seja, a intenção do leitor, a do próprio texto e a do autor. Outro pródigo ponto do capítulo são os apontamentos acerca da dificuldade de apreender o fato histórico em si, ou seja, compreende-lo em sua essência, pois cada apreensão, seja do leitor ou do autor, deforma-o, modelao. Em consonância a isso é discorrido pelo autor que a realidade hagiográfica tem menos uma visão positiva e materialista da história, pois não almeja suas análises dos fenômenos religiosos por meio historicista, mas sim por meio de seus símbolos, metáforas, alegorias e outros meios que constituem a linguagem religiosa.

Ainda no que diz respeito a este capítulo quinto nos é explicitado que todo santo recriado por uma nova hagiografia, antes mesmo disso, 
já era um santo consagrado pela tradição, todavia ao ser recriado ganha um novo corpo individual e social ao se inserir em um outro homem histórico e o hagiógrafo fica responsável por inseri-lo em um novo espaço-temporal. Esse processo, segundo o autor, se desemboca por um produto da imaginação que busca alicerçar insuficiências mundanas do presente. Esse modelo de santidade que se almeja é sempre uma construção baseada no coletivo, pois a imaginação é o ato de um ser social e obedece a esquemas de reorganização que são comuns a um grupo. $\mathrm{O}$ autor enfatiza que o imaginário gesta as hagiografias e exerce sobre elas um poder de realização, o poder da retomada. Amaral nos conta que todo modelo de santidade, seja qual for, partirá de Cristo, dessa forma a fonte de seu trabalho será as Sagradas Escrituras, portanto, ressalta que na Antiguidade Cristã havia interesses ideológicos, e que os seus contemporâneos leram as Sagradas Escrituras impelidos pelos acontecimentos da época, sobretudo em visões de mundo que estavam permeadas pelo maligno e influídas pela filosofia antiga - neoplatônica e escatológica.

Levando-se em conta o que foi observado, podemos entender o quão profícuo é considerar o imaginário como pedra angular de um entendimento mais pleno acerca da Antiguidade Cristã, visto que o imaginário é interdisciplinar e compreende a vida humana em seu sentido mais amplo e profundo, pois tece seu entendimento no simbólico. Portanto, essa obra de Ronaldo Amaral enalteceu as considerações, maneiras de pensar, críticas e novas caminhos para pesquisas no campo da História. Nesse sentido, sua obra torna-se por si só uma ferramenta teó- 
Cadernos de Clio, Curitiba, v. 7, $\mathrm{n}^{\circ}$ 1, 2016

rica aos interessados em vislumbrar as razões sensíveis dos homens nas hagiografias, sobretudo vistas à luz do imaginário.

Recebido em: 25/04/2016 Aceito em: 03/08/2016 
